\title{
CIRCULAR DICHROISM OF LIGHT-HARVESTING COMPLEXES FROM PURPLE PHOTOSYNTHETIC BACTERIA*
}

\author{
Richard J. Cogdell ${ }^{1}$ and Hugo SCheer ${ }^{2} \uparrow$ \\ IDepartment of Botany, University of Glasgow, Glasgow G128QQ, U.K. and ${ }^{2}$ Botanisches Institut der \\ Universität München, München, Menzingerstr. 67, W. Germany.
}

(Received 13 May 1985; accepted 26 August 1985)

\begin{abstract}
The CD spectra of a range of antenna complexes from several different species of purple photosynthetic bacteria were recorded in the wavelength range of 190 to $930 \mathrm{~nm}$. Analysis of the far UV $\mathrm{CD}$ (190 to $250 \mathrm{~nm}$ ) showed that in each case except for the B800-850 from Chr. vinosum the secondary structure of the light-harvesting complexes contains a large amount of $\alpha$-helix $(\geqslant 50 \%)$ and very little $\beta$-pleated sheet. This confirms the predictions of the group of Zuber of a high $\alpha$-helical content based upon consideration of the primary structures of several antenna apoproteins. The CD spectra from the carotenoids and the bacteriochlorophylls show considerable variations depending upon the type of antenna complex. The different amplitude ratios in the CD spectrum for the bacteriochlorophyll $\mathrm{Qy}, \mathrm{Ox}$ and Soret bands indicate not only different degrees of exciton coupling, but also a strong and variable hyperchromism (Scherz and Parson, 1984a, b).
\end{abstract}

\section{INTRODUCTION}

The antenna systems of purple photosynthetic bacteria contain a small number of well-defined bacteriochlorophyll-proteins (Bachmann et al., 1983; Brunisholz et al., 1984; Cogdell and Thornber, 1980; Cogdell et al., 1983; Feick and Drews, 1979; Glazer 1983; Hayashi and Morita, 1980; Sauer and Austin, 1978; Thornber 1970). In general these are composed of 2-3 low-molecular weight polypeptides, 2-3 molecules of bacteriochlorophyll $a$ or $b$ and 1-2 molecules of carotenoid. This is distinctly different from green plant antennas, which contain larger polypeptides. It should be noted, however, that the bacterial antennas are only isolated in their native states (as judged by their retention of the native absorption spectra) so long as they remain aggregated (MW 80-100 kDa).

The antenna complexes are integral membrane proteins and as such can be solubilized by detergents. Once they have been solubilized they can be isolated essentially free of other components. Depending on the detergent used, the size of the complexes varies considerably (Niedermann, 1983; van Grondelle et al., 1983; Kramer et al., 1984). The smallest functional unit (as defined by retention of the native absorption spectrum and efficient energy transfer among its pigments) usually has an apparent molecular weight of appx. $100 \mathrm{kDa}$ (Picorel et al., 1984; Peters and Drews, 1983a; Shiozawa et al., 1982; Miller, 1982; Jay et al., 1984; Kramer et al., 1984). This corresponds to an aggregate of about six of each of the individual subunits, 12-18 molecules

"Dedicated to the memory of Warren L. Butler.

tTo whom correspondence should be addressed. of bacteriochlorophyll and 6-12 molecules of carotenoid in a rather dense packing.

Recently, more than ten of the antenna apoproteins from five different species of the photosynthetic bacteria have been sequenced (Brunisholz et al., 1984a, 1984b; Gogel et al., 1983; Tadros et al., 1983; Theiler et al., 1984; Brunisholz et al., 1985). In general all the polypeptide subunits contain three distinct structural domains: a central hydrophobic core and which is flanked by rather polar $\mathrm{N}$ - and $\mathrm{C}$-terminal regions. These antenna apoproteins have 50-65 amino acids and contain 1 or 2 conserved histidine residues within their hydrophobic sequence. Consideration of these primary structures has naturally led to the suggestion that the central hydrophobic region might be folded into a single, membrane-spanning $\alpha$-helix. It has also been suggested that the conserved histidine residues could serve as the fifth ligands to the magnesium ion at the centre of the bacteriochlorophyll molecule, just as is seen in the bacteriochlorophyll $a$ protein from Prosthecochloris aestuarii (Fenna et al., 1977; Olson 1978).

In spite of all the sequence data on the antenna apoproteins little is known about the detailed structure of the intact antenna complexes and the spatial relationships among the chromophores within them. In the absence of direct structural data from X-ray diffraction, linear and circular dichroism provide an indirect spectroscopic method with which the structure of the chromophores (Sauer, 1975) and the polypeptides (Chen et al., 1972; Saxena and Wettlaufer, 1971; Provencher and Glockner, 1981) can be investigated. The chromophore derived bands of several antenna complexes have been analyzed, in 
particular in the NIR, $\ddagger$ and strong coupling among the chromophores has been suggested. CD data on bacteriochlorophyll $a$ containing, membrane-derived complexes and/or membrane fractions is available for Rp. sphaeroides (Bolt et al., 1981b; Kramer et al., 1984; Miyazaki et al., 1979), Rp. palustris (Hayashi et al., 1982; Miyazaki and Morita, 1981), Rp. capsulata (Bolt et al, 1981a), Rs. rubrum (Sauer and Austin, 1978) and Chr. vinosum (Hayashi et al., 1981; Miyazaki and Morita, 1981). For CD spectra of other bacteriochlorophyll proteins the following references can be consulted (Picorel et al., 1984; Steiner and Scheer, 1985).

The antenna complexes of purple bacteria have been classified phenomenologically into four major types according to the approximate position (derived from a well investigated "type complex") and the relative amplitudes of the near infrared absorption bands. Since the exact positions of the bands are somewhat variable, the individual complexes are then referred to by $B(\lambda)$, with the precise wavelength(s) indicated (see Thornber et al., 1984).

So far the most detailed analyses has been carried out on the B800-850 complex from $R p$. sphaeroides (Kramer $e t$ al., 1984 and references cited). But even in this case the spectra only cover the visible and NIR ranges. Very few data are hitherto available for the spectral region below $250 \mathrm{~nm}$, the region which gives information on the secondary structure of the apoproteins (Breton and Nabedryk, 1984). In this report we wish to present $C D$ data on nine different antenna complexes from four different species, covering the wavelength range from $190-930 \mathrm{~nm}$. Especially interesting are the antenna complexes from Rs. acidophila. This species is of note because, depending upon wild-type strain used, it can contain all four types of antenna complexes (Cogdell et al., 1983).

\section{MATERIALS AND METHODS}

Cells of $R p$. sphaeroides strain 2.4.1., Rp. acidophila strains 7750 and 7050 and $R s$. rubrum strain $\$ 1$ were grown photosynthetically as previously described (Cohen-Bazire et al., 1977; Pfennig, 1969). Cells of Chr. vinosum strain D were grown anaerobically in the light on the medium of Hendley (Moritia et al., 1965). In each case the cells were harvested by centrifugation and then disrupted by passage through a French pressure cell at $130 \mathrm{MPa}$. The photosynthetic membranes were then recovered by differential centrifugation as previously described (see Table 1). The various antenna complexes were prepared from the membranes following solubilization in the zwitterionic detergent LDAO. The details of the preparations are summarized in Table 1.

The absorption spectra of the complexes were measured with a DMR 22 (Zeiss, Oberkochen) or a model 320 spectrophotometer (Perkin Elmer, Überlingen). The optical pathlength was $1 \mathrm{~cm}$ throughout. Due to the measuring geometry, the instrument is rather sensitive to scattering as seen in the baseline slope of some of the complexes. The extinction coefficients of the NIR bacteriochlorophyll absorption bands of the various antenna complexes were determined by the method of Clayton and Clayton (1981), by extraction of the pigments into a $7: 2$ mixture $(\mathrm{vol} / \mathrm{vol})$ of acetone and methanol. The assumptions used in these determinations with respect to the number of bacteriochlorophyll a molecules per "minimal unit" of each antenna complex are detailed in Table 2.

The CD spectra were recorded with a dichograph V (ISA Jobin-Yvon, München) equipped with a Silex (Leonard, Lille) data handling system. A red-sensitive photomultiplier (RS 376, Hamamatsu) was used at wavelengths above 750 $\mathrm{nm}$. The antenna solutions had an optical density $\leqslant 0.8 / \mathrm{cm}$ at the NIR maximum. Their absorption spectra were recorded before and after the accumulation of the $C D$ spectra to ensure that no denaturation had occurred during the measurements. The optical pathlength was $1 \mathrm{~cm}$ between 250 and $1000 \mathrm{~nm}$ and $1 \mathrm{~mm}$ below $250 \mathrm{~nm}$. The secondary structure of the antenna apoproteins is estimated from the mean residue molar ellipticities at $222 \mathrm{~nm}$ (Chen $e t$ al., 1972) or by the fitting procedure of Provencher and Glöckner (1981), based on 11 polypeptides of known secondary structures. Both methods require the knowledge of the concentration of the antenna complexes, or more precisely of the amino acid residues. These were deter-

Table 1. Preparation guide for the antenna complexes

\begin{tabular}{llc}
\hline Type of complex & \multicolumn{1}{c}{ Method of purification } & References \\
\hline B890 from $R$ s. rubrum & $\begin{array}{l}\text { Low LDAO to remove RC's, higher LDAO to solubilize B890, two } \\
\text { passes over DEAE cellulose }\end{array}$ & $1,2,3$ \\
B800-850 from $R p$. sphaeroides & $\begin{array}{l}\text { Low LDAO to remove RC's, higher LDAO to solubilize B800-850, } \\
\text { two passes over DE52. }\end{array}$ & 3,4 \\
$\begin{array}{l}\text { B800 and B800-850 'type I' from } \\
\text { Rp. acidophila } 7750\end{array}$ & Antenna and RC's solubilized in 1\% LDAO, two passes over DE52 & 5 \\
$\begin{array}{l}\text { B800-820, B } 800-850 \text { 'type II' } \\
\text { from Rp. acidophila 7050 }\end{array}$ & Same procedure as strain 7750 \\
$\begin{array}{l}\text { B800-850 'type II', B800-840, } \\
\text { B800-820 from Chr. vinosum }\end{array}$ & Solubilized with 1\% LDAO, resolved by two passes over DE52 & 5 \\
\hline
\end{tabular}

LDAO was used as the detergent in all cases. References: 1: Vadeboncoeur et al., 1979; 2: Picorel et al., 1983; 3: Cogdell et al., 1982; 4: Cogdell et al., 1980; 5: Cogdell et al., 1983.

$\ddagger$ Abbreviations: CD, circular dichroism; Chr, Chromatium; LDAO, lauryldimethylaminoxide; NIR, near infrared; RC, reaction center; $R p$, Rhodospeudomonas, $R s$, Rhodospirilhtm; SDS, sodium dodecyl sulfate. 
Table 2.

\begin{tabular}{|c|c|c|c|c|c|c|c|c|c|c|}
\hline \multirow[t]{2}{*}{ Species } & \multirow[t]{2}{*}{$\begin{array}{l}\text { Antenna } \\
\text { type }\end{array}$} & \multicolumn{3}{|c|}{$\begin{array}{l}\text { Contents per } \\
\text { minimal unit } \neq\end{array}$} & \multirow[t]{2}{*}{$\begin{array}{c}\epsilon_{\mathrm{NIR}} \times 10^{-3} \\
\left(\lambda_{\mathrm{max}}\right)\end{array}$} & \multicolumn{3}{|c|}{$\begin{array}{l}\text { Relative anisotropies } f \text { and position }(\mathrm{nm}) \\
\text { of CD-bands related to: }\end{array}$} & \multirow[t]{2}{*}{$\left(\begin{array}{c}{[\bar{\theta}]_{\text {res }}^{222}} \\
\times 10^{-3}\end{array}\right)$} & \multirow{2}{*}{$\begin{array}{c}\text { Calculated } \\
\text { secondary } \\
\text { structure }\end{array}$} \\
\hline & & $\mathrm{AA}$ & Bchl & Car & & $\begin{array}{l}\text { Bacterio- } \\
\text { chlorophylls }\end{array}$ & Carotenoids & Peptides\$ $§$ & & \\
\hline $\begin{array}{l}\text { Rs. } \\
\text { rubrum ** }\end{array}$ & B 890 & $\begin{array}{l}\alpha: 52 \\
\beta: 54\end{array}$ & 2 & 1 & $123(890)$ & $\begin{array}{l}+0.71++(876) \\
+0.21++(798) \\
+0.2 \quad(590) \\
-1.25++(325)\end{array}$ & $\begin{array}{l}+0.19(560) \\
+0.13(526)\end{array}$ & $-4.39(222)$ & $-16,2$ & $73: 4: 21$ \\
\hline $\begin{array}{l}R p \\
\text { acidophila } \\
7750\end{array}$ & B 880 & $2 \times 65^{*}$ & 2 & 1 & $284(880)$ & $\begin{array}{l}+0.65+\div(880) \\
+0.43+\div(796) \\
+0.3 \quad(597) \\
-1.44+\div(326)\end{array}$ & $\begin{array}{l}+0.26(559) \\
+0.34(525)\end{array}$ & $-6.0(222)$ & -21.9 & $100: 0: 0$ \\
\hline $\begin{array}{l}R p . \\
\text { sphaeroides } \\
2.4 .1\end{array}$ & $\begin{array}{l}\text { B } 800- \\
-850\end{array}$ & $\begin{array}{l}\alpha: 51 \\
\beta: 54\end{array}$ & 3 & $1 \|$ & $319(850)$ & $\begin{array}{l}+3.44+\dagger(856) \\
-1 \quad+\dagger,+\dagger(814) \\
+0.13 \quad(605) \\
-1.13 \quad(355)\end{array}$ & $\begin{array}{l}+1.06(535) \\
+0.71(510)\end{array}$ & $-2.96(222)$ & -32.1 & $53:-: 47$ \\
\hline $\begin{array}{l}\text { Rp. } \\
\text { acidophila } \\
7750\end{array}$ & $\begin{array}{l}\text { B } 800- \\
-850 \\
\text { Typ I }\end{array}$ & $\begin{array}{l}2 \times 55^{*} \\
1 \times 65\end{array}$ & 3 & 1 & $323(855)$ & $\begin{array}{l}+2.12+\div(878) \\
-1.06+\div(810) \\
+0.21 \quad(608) \\
-0.5 \quad(355)\end{array}$ & $\begin{array}{l}+0.64(534) \\
+0.49(498)\end{array}$ & $-2.97(222)$ & -26.9 & $81: 9: 10$ \\
\hline $\begin{array}{l}\text { Rp. } \\
\text { acidophila } \\
7050\end{array}$ & $\begin{array}{c}\text { B } 800- \\
-850 \\
\text { Typ II }\end{array}$ & $2 \times 55^{*}$ & 3 & 1 & $260(803)$ & $\begin{array}{l}-1.47++(810) \\
+1.47++(865) \\
+1.03 \quad(591) \\
+0.36 \quad(350)\end{array}$ & $\begin{array}{l}+0.68(527) \\
+0.38(503)\end{array}$ & $-4.09(222)$ & -32.1 & $100: 0: 0$ \\
\hline $\begin{array}{l}R p . \\
\text { acidophila } \\
7050\end{array}$ & $\begin{array}{c}\text { B } 800- \\
-820\end{array}$ & $2 \times 55^{*}$ & 3 & 1 & $260(803)$ & $\begin{array}{lr}-1 & \dagger \dagger, \ddagger \neq(810) \\
+0.8 & \dagger \dagger,+千(842) \\
+0.77 & (588) \\
+0.28 & (346)\end{array}$ & $\begin{array}{l}+0.49(525) \\
+0.25(488)\end{array}$ & $-5.90(222)$ & -46 & $\$ \$$ \\
\hline $\begin{array}{l}\text { Chr. } \\
\text { vinosum }\end{array}$ & $\begin{array}{l}\text { В } 800- \\
-850 \\
\text { Typ II }\end{array}$ & n.d. & 3 & 1 & $205(795)$ & $\begin{array}{ll}+1.95++(803) \\
-0.27 & (850) \\
+0.29 & (583) \\
+0.84 & (362)\end{array}$ & $+1.14(530)$ & $-2.76(222)$ & $-16.9 \dagger$ & $28: 72: 0 \dagger$ \\
\hline $\begin{array}{l}\text { Chr. } \\
\text { vinosum }\end{array}$ & $\begin{array}{c}\text { B } 800- \\
-840\end{array}$ & n.d. & 3 & 1 & $205(795)$ & $\begin{array}{ll}+2.22+t(806) \\
-0.7 & (845) \\
+0.34 & (576) \\
+0.90 & (362)\end{array}$ & $+1.17(540)$ & $-7.21(222)$ & $-44.9+$ & $\$ \$$ \\
\hline $\begin{array}{l}\text { Chr. } \\
\text { vinosum }\end{array}$ & $\begin{array}{c}\text { B } 880- \\
-820\end{array}$ & n.d. & 3 & 1 & $262(795)$ & $\begin{array}{l}+3.03+\mp(805) \\
-0.85 \quad(850) \\
+0.40 \quad(575) \\
+1.16 \quad(360)\end{array}$ & $+1.5(538)$ & $-6.18(222)$ & $-21.1 t$ & $65: 35: 0 \dagger$ \\
\hline
\end{tabular}

${ }^{*}$ Estimated values based on SDS polyacrylamide gel electrophoretic comparison with antenna polypeptides of known size.

†Values estimated assuming 110 amino-acid residues and 3 bacteriochlorophyll molecules per minimal unit.

$+\mathrm{Bchl}=$ bacteriochlorophyll $a, \mathrm{Car}=$ carotenoids, $\mathrm{AA}=$ amino acid residues.

$\$ \in$ given in $\left(M^{-1} \mathrm{~cm}^{-1} \times 10^{-3}\right)$. The values quoted are probably good to $\pm 10 \%$.

$\|$ A recent report (Kramer et al., 1983) has suggested that this complex contains bacteriochlorophyll $a$ and carotenoids in the ratio 3:2, however, this remains to be confirmed.

\$Relative anisotropies $\left(\Delta \mathrm{E} \times 10^{3} / \mathrm{E}_{\max }, \mathrm{NIR}\right)$. The values are defined as the ratios of the circular dichroism $(\Delta \mathrm{E})$ at the wavelength indicated in brackets, and the maximum absorption of the most intense near-infrared absorption band, multiplied by $10^{3}$. The wavelengths given in brackets correspond to the CD extrema (absorption type CD bands), or zero crossings ( $\mathrm{S}$-shaped CD bands, see h).

${ }^{* *} \mathrm{CD}$ data taken from the sample containing residual reaction centers (see Fig. $1 \mathrm{~A}$ and discussion).

$\uparrow+S$-shaped CD band. The sign is denoted positive if the higher energetic lobe is positive.

$\ddagger$ Estimated value.

$\$ \$$ No reasonable fit with CONTIN analysis, the values for $\alpha$-helical contents were $>100 \%$ (see discussion). 
mined using (i) the extinction coefficients determined spectrophotometrically (see above), and (ii) the number of amino acids and the amino acid/bacteriochlorophyll ratios given in Table 2. The number of amino acids are based either on the known primary structures or, where this data are absent, on best-estimates from SDS-polyacrylamide gel electrophoretic comparisons.

\section{RESULTS AND DISCUSSION}

The results are summarized in Table 2 and illustrated in Figs. 1-10. The complexes examined in this study belong to four types B880, B800-850 type I and II and "others". This classification is based on the approximate position and the relative intensities of the near-infrared absorption bands, but the borderlines are not yet well defined. In the case of the B880 and B800-850 "type I" complexes, the close relationship of spectroscopically similar antenna complexes from different species has also been supported by primary structure data, even though the exact positions of the absorption maxima are somewhat species dependent. The complexes belonging to these two types are therefore discussed in separate sections irrespective of their origin. The remaining complexes (B800-850 "type II" and "others") are grouped according to their parent organisms. The peptide region $(190-250 \mathrm{~nm})$ is presented for all the complexes in a separate section.

\section{B880 Complexes}

Two antenna complexes of this type have been examined, B880 from Rp. acidophila strain 7750 (Fig. 2) and B890 from Rs. rubrum strain S1 (Fig. 1A, $B)$. In general, the $B 880$ complexes are rather more unstable than either the $\mathrm{B} 800-850$-complexes or the B800-820-complexes, and are quite difficult to separate completely from reaction centres (Bachmann $e t$ al., 1983; Bolt et al., 1981; Feick and Drews, 1978; Tonn et al., 1972; Hayashi et al., 1982; Peters and Drews, 1983; Picorel et al., 1984; Sauer and Austin, 1978). The preparations shown in Figs. $1 \mathrm{~A}$ and 2 contained small amounts of reaction centers, and undoubtedly some of the absorption and $C D$ bands around $800 \mathrm{~nm}$ are due to this. Based on CD data (not shown) for reaction centers of Rs. rubrum S1, and assuming that all the absorption at $800 \mathrm{~nm}$ in the sample shown in Fig. 1A is due to reaction centers, about $50 \%$ of the optical activity at $800 \mathrm{~nm}$ in the "contaminated" B 890 preparation can be accounted for. A similar upper limit (40\%) is estimated for B880 from $R p$. acidophila, if the same optical activity for the reaction centers is assumed. Both results would support an inherent optical activity of the B880 complexes in the $800 \mathrm{~nm}$ region, which corroborates earlier reports on B 890 from Rs. rubrum (Sauer and Austin, 1978) and B870 from Rp.palustris (Hayashi et al., 1982).

There are, however, data showing no $C D$ signal around $800 \mathrm{~nm}$ for a B875 complex from $R p$. sphaeroides purified by lithium dodecyl sulfate -
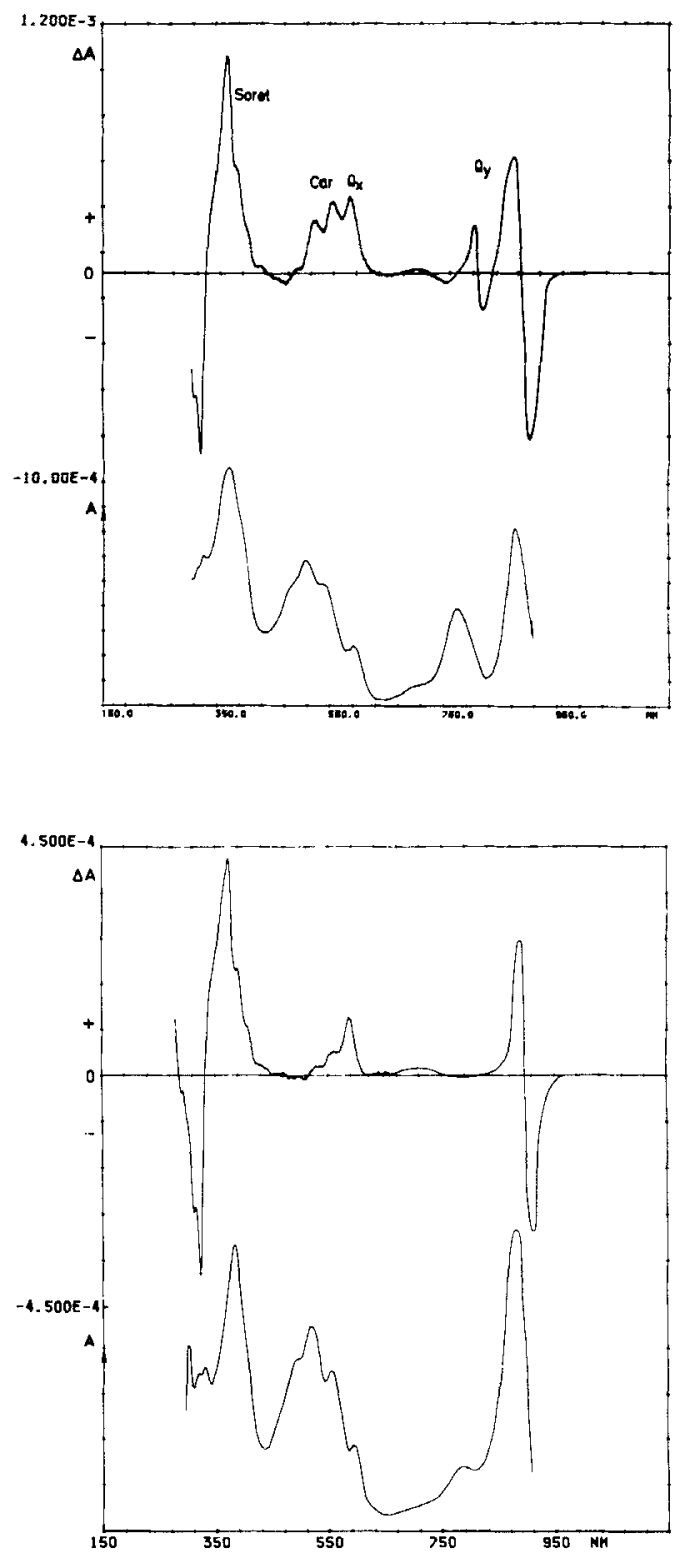

Figure 1. Absorption (bottom) and circular dichroism spectra (top) of the B890 antenna complex from Rhodospirillum rubrum $\mathrm{S} 1$ in the near infrared, visible and near ultraviolet spectral region. The sample shown in (A) contained a reaction center contamination if judged from the absorption around $800 \mathrm{~nm}$, whereas the sample shown in (B) was free of it. See Table 2 for the wavelength positions and for the extinctions and ellipticities, respectively, of the major bands.

polyacrylamide gel electrophoresis (Bolt et al., 1981b). We did obtain similar results with a B890 preparation from $R s$. rubrum which was more extensively purified by DEAE cellulose chromatography (Fig. 1B). This sample lacked an absorption band around $800 \mathrm{~nm}$, and did not show any CD signal in this region either. The conflicting results may reflect changes in the state of the labile complexes induced 


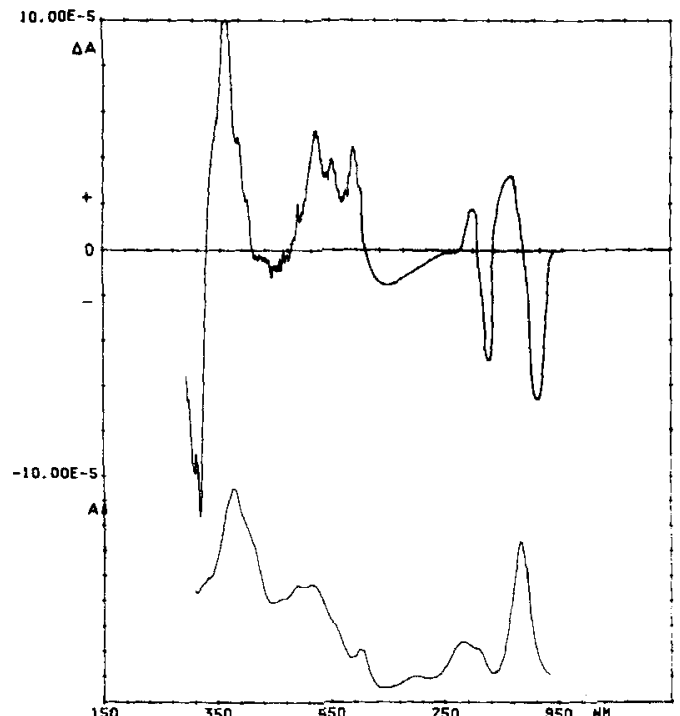

Figure 2. Absorption and circular dichroism spectra of the B880 antenna complex from Rhodopseudomonas acidophila 7750. See Figure 1 and Table 2 for details.

by the separation procedure. This is indeed supported by a comparison of other spectral regions of the two preparations shown in Figs. 1A and B.

There is in particular a decrease of two bands in the carotenoid region in the "pure B890". Since reaction centers of Rs. rubrum S1 show only a weak and unstructured signal in this region, this difference, too, cannot be explained readily by the removal of reaction centers. It is, therefore, likely that the native complex has some optical activity in the $800 \mathrm{~nm}$ region which is very sensitive to environmental changes and easily abolished together with the carotenoid related optical activity during purification.

Apart from the optical activityaround $800 \mathrm{~nm}$ the $\mathrm{CD}$ spectra of the two complexes studied here are qualitatively and quantitatively similar (Figs. 1 and 2). They both show a weak exciton couplet centered in the NIR absorption band, and their absorption intensity ratios in the Qy, Qx and Soret bands are similar to those for free bacteriochlorophyll $a$ in organic solution, e.g. in ether. This suggests that the absorption and CD spectra can be explained purely in terms of exciton splitting without the need to invoke any hypo- or hyperchromic effects (Scherz and Parson, 1984a). The Qx band of the bacteriochlorophyll is only moderately anisotropic and appears to be non-conservative with a net positive sign.

The CD signals arising from the carotenoid absorption bands in the $500-570 \mathrm{~nm}$ region are positive and moderately anistropic. The only significant difference between the signals from the two complexes is the ellipticity ratio of the bands at 560 and $525 \mathrm{~nm}$, which is $\leqslant 1$ in $R p$. acidophila and $\geqslant 1$ in Rs. rubrum. It should be noted, however, that the carotenoid optical activity appears to be rather sensitive to the preparation procedure (see above).

\section{B800-850-type I complexes}

Type I B800-850-complexes have been prepared from $R p$. sphaeroides strain 2.4.1 (Fig. 3) and $R p$. acidophila strain 7750 (Fig. 4). Both the absorption and $C D$ spectra of these two antenna complexes are again rather similar in general appearance, but they do show some detailed differences.

The NIR absorption spectra of these complexes are characterized by two strong absorption bands

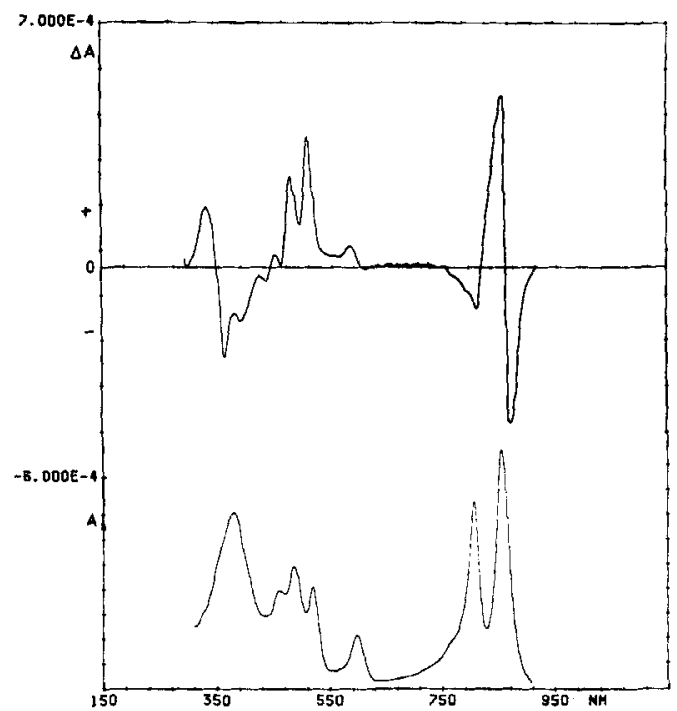

Figure 3. Absorption and circular dichroism spectra of the B800-850 antenna complex from Rhodopseudomonas sphaeroides. See Figure 1 and Table 2 for details.

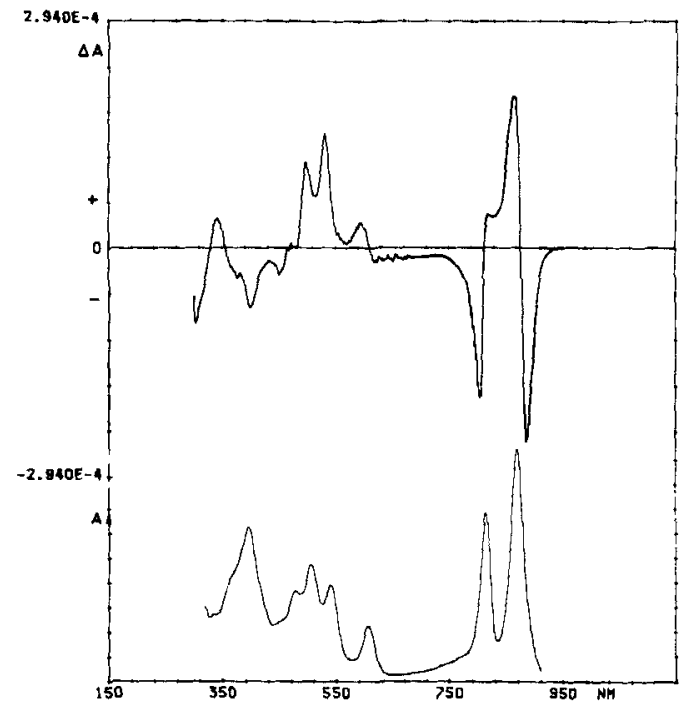

Figure 4. Absorption and circular dichroism spectra of the B800-850 type I antenna complex from Rhodopseudomonas acidophila 7750. See Figure 1 and Table 2 for details. 
centred at about $800 \mathrm{~nm}$ and about $850 \mathrm{~nm}$. These have an intensity ratio (at room temperature) of about $1: 1.5$, respectively. The $C D$ spectrum in the NIR can be rationalized by assuming that there are two overlapping and intense exciton couplets centred in these two absorption bands. The shorter wavelength couplet is positive and the longer wavelength one negative. In Rp. sphaeroides (Fig. 3) the longer wavelength couplet has almost twice the anisotropy compared to that in $R p$. acidophila (Fig. 4).

The CD signal from the $\mathrm{Qx}$ band of the bacteriochlorophyll is only weak. It shows a single slightly asymetric " $\mathrm{S}$ " which is superimposed on a broad positive band of rather small intensity. The Qx band of the bacteriochlorophyll chromophore in the complex from Rp. acidophila (Fig. 4) is rather more intense both in absorption and in the CD spectrum, compared with the signal from the Rp. sphaeroides complex (Fig. 3).

The most pronounced differences in the CD spectra of the two complexes are seen in the Soret region. Here the negative extrema at about $365 \mathrm{~nm}$ and at about $400 \mathrm{~nm}$ are of quite different intensities in the two complexes. The ratio of the intensity at about 365 $\mathrm{nm}$ to that at about $400 \mathrm{~nm}$ is $5: 3$ in the complex from Rp. sphaeroides (Fig. 3) and 1:2 in the complex from $R p$. acidophila (Fig. 4). Most of the absorption in this region is due to bacteriochlorophyll $a$, although there is also residual absorption due to the carotenoids. This ambiguity makes it difficult to decide upon the origin of these differences. Dialysis of the B800-850 complex against LiDS (Clayton and Clayton, 1981), by which a "low B800" complex is formed, does not alter the optical activity in the Soret region (data not shown). This makes it unlikely, that all differences between the B800-850 complexes from the two organisms are related to a change in the $B 800$ component alone.

The CD spectra reported here for the $\mathrm{B} 800-850$ complex from $R p$. sphaeroides agrees well with those previously reported (Bolt and Sauer, 1981; Kramer et al., 1984; Sauer and Austin, 1978), while the CD spectrum of the 'type I' B800-850 complex from $R p$. acidophila is more closely related to the CD spectrum of the "high" 850 complex from Rp. plaustris (Hayashi et al., 1982). It should be noted, that the NIR CD spectrum of the B800-850 complex from $R p$. sphaeroides obtained at $77 \mathrm{~K}$ (Kramer et al., 1984 ) becomes rather similar to that of $R p$. acidophi$l a$ at room temperature.

\section{'Type II' B800-850- and B800-820-complexes from Rp. acidophila strain 7050}

The general appearance of the absorption and CD spectra of these two antenna complexes is so similar that they may well be considered as two forms of a single complex. Conclusive proof of this view, however, must await further work upon their consti- tuent apoproteins to see whether they are identical or not.

In their absorption spectra the only distinct difference is the position of the red-most bactriochlorophyll $a$ absorption band, either centered at about $850 \mathrm{~nm}$ or about $820 \mathrm{~nm}$. Similarly the CD spectrum of the B800-820 complex (Fig. 6) can be exactly generated just by shifting the negative exciton couplet of the B800-850 complex (Fig. 5) centered at 865 $\mathrm{nm}$ towards the second positive exciton couplet

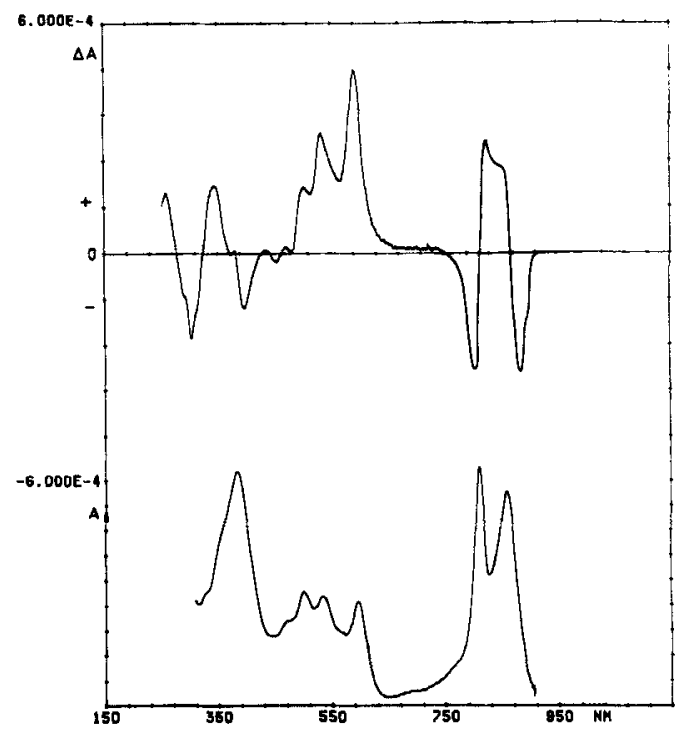

Figure 5. Absorption and circular dichroism spectra of the B800-850 type II antenna complex from Rhodopseudomonas acidophila 7050. See Figure 1 and Table 2 for details.

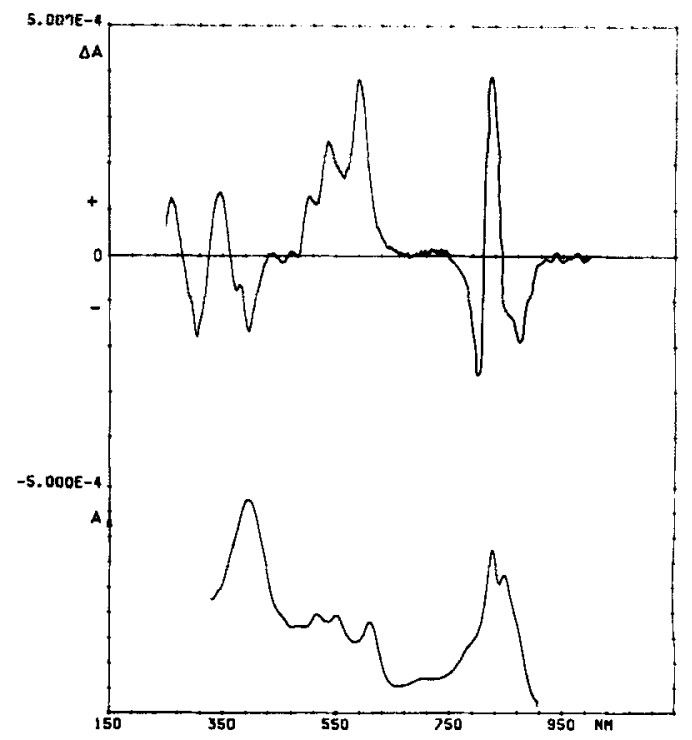

Figure 6. Absorption and circular dichroism spectra of the B800-820 antenna complex from Rhodopseudomonas acidophila 7050. See Figure 1 and Table 2 for details. 
centred at $840 \mathrm{~nm}$, by about $25 \mathrm{~nm}$.

In the range from 250 to $750 \mathrm{~nm}$, the CD spectra of the two complexes are virtually superimposable. The only distinct difference is a blue-shift of the negative shoulder in the bacteriochlorophyll $a$ Soret region. In the B800-850-complex (Fig. 5) it is located at $375 \mathrm{~nm}$, while in the $B 800-820$-complex it is at $371 \mathrm{~nm}$ (Fig. 6). It seems likely that this shift identifies this transition as belonging to the chromophores absorbing at 850 and $820 \mathrm{~nm}$, respectively. A small shift is also seen in the Qx band around $600 \mathrm{~nm}$.

However, perhaps the most noteworthy feature of the entire spectra of both complexes is the intensity of the $\mathrm{Qx}$ band. Its absorption amounts to almost $50 \%$ of the most intense NIR absorption band. This compares with values of about $20 \%$ for this intensity in the 'type I' B800-850 complex from $R p$. sphaeroides (Fig. 3) and about $25 \%$ in free, monomeric bactriochlorophyll $a$. Its intensity is even more pronounced in the CD spectrum, where it shows as a single positive band around $590 \mathrm{~nm}$, which is almost as intense as the NIR CD bands and much stronger than the carotenoid bands.

A comparison of the two type I B800-850 complexes described in the previous section with the two complexes described here, suggests that there is probably a gradual transition among the different types. One extreme would be the 'type I' B800850-complex from $R p$. sphaeroides (Fig. 3). Its absorption spectrum is characterized by a strong red-most band, a weaker second NIR band and a weak absorption band in the bacteriochlorophyll $\mathrm{Ox}$ region. The CD spectrum of this complex is dominated by an intense negative exciton couplet related to the $850 \mathrm{~nm}$ absorption band and the carotenoid bands in the $450-550 \mathrm{~nm}$ region. The other extreme is the B800-820 complex from $R p$, acidophila strain 7050 (Fig. 6). In the absorption spectrum the intensity order of the two NIR bands is reversed, and the bacteriochlorophyll $\mathrm{Qx}$ band is greatly increased in intensity. The same is true for the CD spectrum, where the positive exciton couplet related to the 800 $\mathrm{nm}$ band and the $\mathrm{Qx} C D$ band are the dominant features in the NIR and visible spectral region, respectively. The 'type I' and 'type II' B800-850complexes from $R p$. acidophila are intermediates between these two extremes (Figs. 4 and 5).

Scherz and Parson (1984a) have recently developed a theory which relates absorption and $C D$ spectra of bacteriochlorophyll and bacteriopheophytin aggregates (Gottstein and Scheer, 1983; Scherz and Parson, 1984b) to their spacial arrangements. In addition to exciton splitting it takes into account hyper- and hyperchromic effects among the Qy, Qx and Soret bands of the pigments. In the complexes investigated by these authors the $\mathrm{Oy}$ band has gained in intensity at the expense of the other two absorption bands. This clearly relates to the 'type I' B $800-850$ complexes. Since the hyperchromism is sensitive to the geometry of the interacting pigments, in the 'type
II' B800-850-complexes the bacteriochlorophylls probably have a different geometry. In contrast to the bacteriochlorophyll related $C D$ bands, the carotenoid CD bands are essentially the same in the different complexes. (Slight changes in intensities probably reflect differences in carotenoid composition from complex to complex). If these bands were as sensitive to structural parameters as the bacteriochlorophyll bands are, then this would indicate a more conservative geometry for the carotenoids within the two types of complexes. The carotenoid related $C D$ bands are the most conservative in the B800-850-complexes studied here, including those derived from Chr. vinosum (see below).

\section{$B 800-850, B 800-840$ and $B 800-820$ from $\mathrm{Chr}$. vinosum*}

These three complexes differ in their absorption spectra in the position of the red-most NIR band. Just as seen in the 'type II' B800-850 complex from $R p$. acidophila strain (Fig. 5), this red-most absorption band is less intense than the second band at $800 \mathrm{~nm}$. The CD spectra of these two complexes are quite different, however, and suggest that they should no longer be classified as the same type.

Allowing for the shift in the red-most NIR band, the CD spectra of all three complexes from $\mathrm{Chr}$. vinosum (Figs. 7-9) are very similar to one another, but quite different from those of the antenna complexes from $R p$. acidophila (Figs. 4-6). The NIR

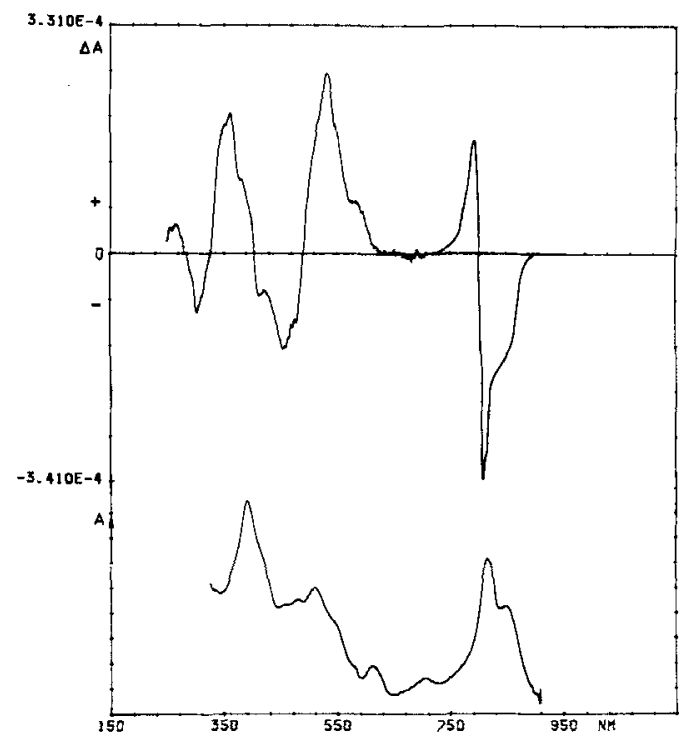

Figure 7. Absorption and circular dichroism spectra of the B800-850 antenna fraction isolated from Chromatium vinosum. See Figure 1 and Table 2 for details.

*The numbers refer to the wavelength of the NIR absorption maxima. These absorption maxima are somewhat variable depending upon the isolating procedure. It may well be that the B800-840-complex (Fig. 8) described here is only a spectrally altered form of the more well known B800-850 complex (Fig. 7), which is a 'type II' complex. 


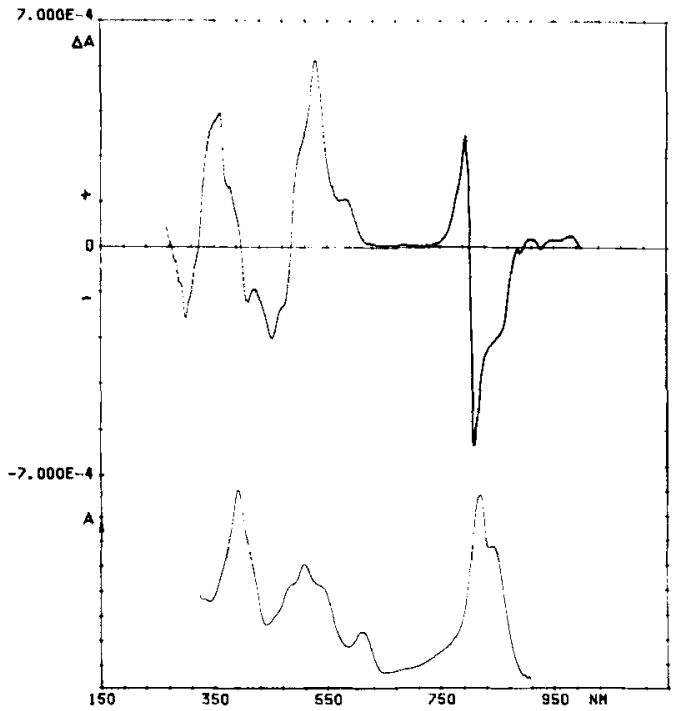

Figure 8. Absorption and circular dichroism spectra of the B800-840 antenna fraction isolated from Chromatium vinosum. See Figure 1 and Table 2 for details.

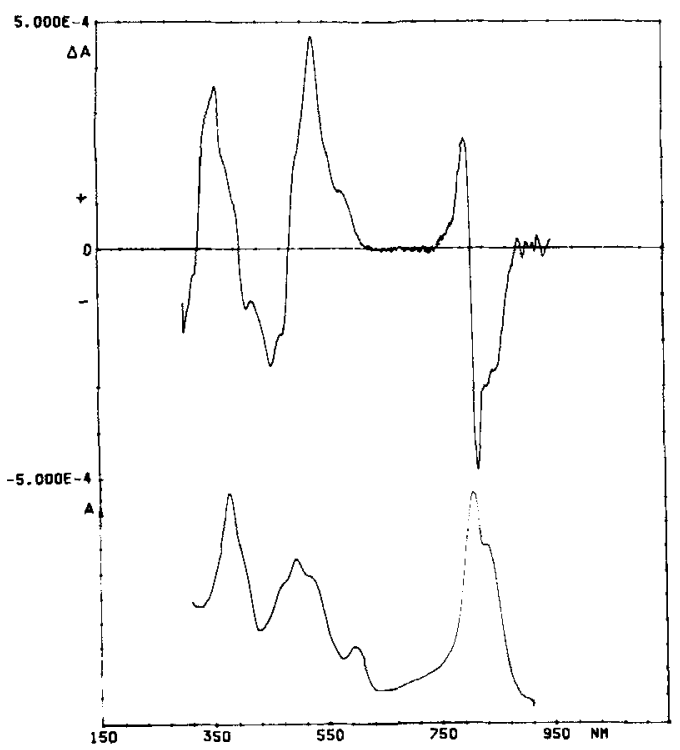

Figure 9. Absorption and circular dichroism spectra of the B800-820 antenna fraction isolated from Chromatium vinosum. See Figure 1 and Table 2 for details.

region is strongly non-conservative, with a net negative sign. It may be composed of a single negative band related to the red-most NIR absorption band $(820,840$ or $850 \mathrm{~nm}$ respectively) and a split CD band related to the $800 \mathrm{~nm}$ absorption. The CD signal from the $\mathrm{Qx}$ band is small, the one in the Soret region is non-conservative with a net positive sign and shows some structure. The carotenoid related CD bands are very intense, but poorly resolved. The poor spectral resolution in the carotenoid region, which is also seen in the absorption spectrum, is probably the consequence of the fact, that the antenna complexes from Chr. vinosum contain a mixture of carotenoids (mainly Rhodopin, Spirilloxanthin, Rhodovibrin and Lycopene, Schmidt et al., 1965).
The NIR-CD spectra of four different antenna "complexes" from $\mathrm{Chr}$. vinosum have been reported (Hayashi et al., 1981). The spectra shown here are quite similar to the "low B850-fraction B" and "fraction C", which corresponds, in our nomenclature, to the B800-850- and B800-820-complexes, respectively. The fractions studied by Hayashi et al. (1981) were shown to be in their native states since summing of the spectra from the individual fractions generated the spectrum seen in the intact photosynthetic membrane.

\section{The peptide region}

This region has been investigated in order to obtain information on the secondary structure of the antenna peptides. The main results are summarized in Table 2. Two CD spectra covering the full range from 190-950 nm are shown in Figs. 10 and 11. The data have been analysed by the method of Provencher and Glöckner (1981), which is based on a curve fit using 11 hydrophilic globular proteins as the basis set. The results (Table 2) show a remarkably high degree of $\alpha$-helix content for most of the antenna complexes. These results do not only corroborate secondary structure predictions of a central helical stretch of about 20 amino acids spanning the membrane, which

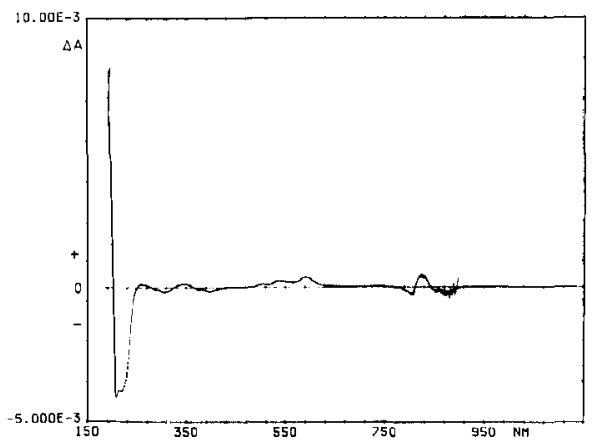

Figure 10. The circular dichroism spectrum $(190-950 \mathrm{~nm})$ of the B800-820 antenna complex from Rhodopseudomonas acidophila 7050 plotted at the same sensitivity at all wavelengths.

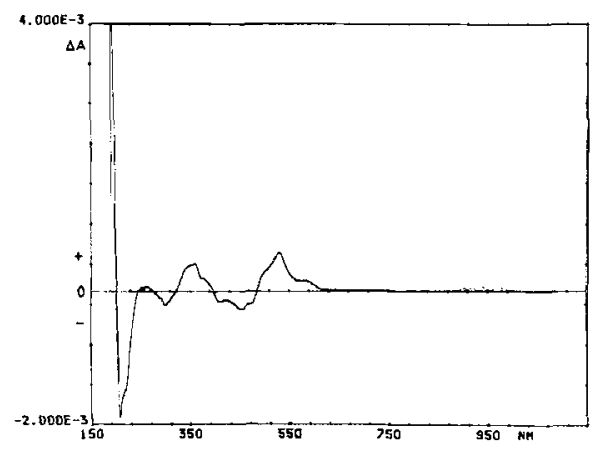

Figure 11. The circular dichroism spectrum (190-950 nm) of the B800-850 antenna fraction isolated from Chromatium vinosum plotted at the same sensitivity at all wavelengths. 
is based on primary structure data (Brunisholz et al., 1984a, b; Gogel et al. , 1983; Tadros et al., 1983, 1984; Theiler et al. , 1984). They also indicate, that the more hydrophilic $\mathrm{N}$ - and $\mathrm{C}$-terminal regions contain some additional $\alpha$-helical structure.

It should be emphasized, however, that these data can presently only be regarded as a trend analysis. There are several factors, whose contributions can presently only be estimated semi-quantitatively. Firstly, the basis set used for the CD analysis does not include a single membrane protein, and reliable conformational data on membrane proteins are as yet very sparse (see e.g. Deisenhofer et al., 1984 and Henderson et al., 1982). A careful analysis of the bacteriorhodopsin secondary structure indicated that the $\alpha$-helix content derived from earlier electron scattering data may in fact be too high, and that the $\mathrm{CD}$ analysis based on hydrophilic globular proteins gives fair estimates (Glaser, 1982).

The second uncertainty (which applies as well to other chromoproteins like e.g. bacteriorhodopsin) concerns the relative magnitudes of the $C D$ bands related to the chromophores and those of the peptide bands in the far UV region. If judged from the two spectra shown in Figs. 9 and 10, which represent two extreme cases, the contributions of the chromophores to the CD spectrum below $230 \mathrm{~nm}$ appear to be relatively minor. To further evaluate this contribution, the far-UV CD spectra of both monomeric and aggregated bacteriochlorophyll $a$ have been recorded. The optical activity of monomeric bacteriochlorophyll $a$ in dioxan or methanol is positive at $200 \mathrm{~nm}$ but so small, that a quantitative determination was not possible. The optical activity of aggregates formed in $20 \%$ aqueous methanol is larger, with a negative extremum $(\Delta E=$ -47) at $203 \mathrm{~nm}$ (not corrected for scattering). Bacteriochlorophyll $a$ aggregates have been discussed as useful models for the state of the pigments in several bacteriochlorophyll $a$ proteins (Gottstein and Scheer, 1983; Scherz and Parson, 1984a, b). Taking into account the stoichiometry of pigments (see below) and amino acid residues in the antenna complexes, this would correspond to a contribution of the pigments to the mean residue ellipticities of appx. 4000. We have encountered considerable $(+/-$ $15 \%$ ) variations in the $\alpha$-helical content by varying the lower wavelength limit of the data set between 190 and $205 \mathrm{~nm}$. These variations may at least in part be due to the chromophore contributions in the range about and below $205 \mathrm{~nm}$, which the program based only on a polypeptide basis set is unable to cope with.

The third uncertainty relates to the chromophoreprotein stoichiometry and concentration of the antenna proteins. The concentration of the pigments can be determined with reasonable accuracy $(+/-$ $10 \%$ ) by the extraction procedure described in materials and methods. The determination of the protein concentration of antenna complexes is a little uncertain and the results depend upon the method used (Cogdell and Lindsay, unpublished observa- tions). Whereas curve fitting procedures should principally be able to adjust the concentration as a third free parameter, the procedure is in practice very sensitive to concentration variations. This problem is pointed out by Provencher and Glöckner (1981) and has also come out clearly from test runs with our data. Reliable data are then only accessible for antenna proteins for which both the number of amino acid residues and the number of bacteriochlorophyll $a$ chromophores in the protomer are known. Of the nine chromoproteins studied, this is true only for B800-850 from $R p$. spheroides and B890 from Rs. rubrum. A careful examination of the pigments derived from $R$. acidophila is in progress (Cogdell et al., unpublished), and the data given in Table 2 for B800-850 type I and B800-820 are probably correct within $+/-20 \%$. Very little is known about the $\mathrm{Chr}$. vinosum pigments, and this is most probably the reason for the extreme values found for its antenna fractions. B800-850 from this species is the only chromoproteins for which the analysis indicates a predominant $\beta$-sheet structure. On the other hand are the residual ellipticities for $\mathrm{B} 800-840$ from $C h r$. vinosum (as well as of the B800-820 complex form $R p$. acidophila) far too high and indicate the presence of more amino acids per bacteriochlorophyll $a$ than anticipated.

The fourth uncertainty is finally the amount of scattering in the samples. From fluorescence data, an upper aggregation limit of 20 has been estimated for B800-850 from Rp. spheroides (Kramer et al., 1983). This corresponds to a molecular weight of about 200 $\mathrm{kDa}$. Since scattering has been found to be insignificant for purple membrane fragments of much larger size (Glaser, 1982), we conclude that this contribution is negligible in the antenna proteins when compared to the other factors.

Whereas the aforementioned limitations restrict the exactness of our conformational analysis of the peptide, the data do suggest a rather large $\alpha$-helical content for all the antenna proteins studied here, except in the case of B800-850 from Chr. vinosum. Breton and Naberdryk (1984) have recently investigated the secondary structure of a B800-850 complex from $R$ p. spheroides by analysing both the far UV CD and IR spectra. Their values $(46 \% \alpha$-helix, 12\% $\beta$ pleated sheet, $42 \%$ 'others') agree well with the results that we have described above. This agreement is encouraging, however, further work is undoubtedly required to completely validate the use of far UV CD spectra for the analysis of the secondary structure of integral membrane chromoproteins.

Acknowledgements-We acknowledge the support of this work by the SERC (R.J.C.) and the Deutsche Forschungsgemeinsschaft (H.S.). Expert technical assistance was provided by Ms. L. Roberts (Glasgow) and Ms. C. Bubenzer (München). We are indebted to Dr. S. Provencher (Heidelberg) for providing us with the CONTIN program for CD analysis and to Dr. A. Scherz (Rehovot) for helpful discussions. 


\section{REFERENCES}

Bachmann, R. C., M. H. Tadros, J. Oelze, and J. Y. Takemoto (1983) Biochem. Intern. 7, 629-634.

Bolt, J. D. and K. Sauer (1981) Biochim. Biophys. Acta 637, 342-347.

Bolt, J. D., K. Sauer, J. A. Shiozawa and G. Drews (1981a) Biochim. Biophys. Acta 635, 535-541.

Bolt, J. D., N. Hunter, R. A. Niederman and K Sauer (1981b) Photochem. Photobiol. 34, 653-656.

Borisov, A. Y., R. A. Gadonas, R. V. Danielius, A. S. Piskarskas and A. P. Razjivin (1982) FEBS Lett. 138. 25-28.

Breton, J. and E. Nabedryk (1984) FEBS Lett. 176, 355-359.

Brunisholz, R. A., F. Suter and H. Zuber (1984a) Hoppe-Seylers Z. Physiol. Chem. 365, 675-688.

Brunisholz, R. A., V. Wiemken, F. Suter, R. Bachofen and H. Zuber (1984b) Hoppe Seylers Z. Physiol. Chem 365, 689-701.

Chen, Y-H., J. T. Yang and H. M. Martinez (1972) Biochemistry 11, 4120-4131.

Clayton, R. K and B. J. Clayton (1981) Proc. Natl. Acad. Sci. USA 78, 5583-5587.

Cogdell, R. J. and J. P. Thornber (1980) FEBS Lett. 122, 1-8.

Cogdell, R. J., J. G. Lindsay, G. P. Reid and G. D. Webster (1980) Biochim. Biophys. Acta 591, 312320 .

Cogdell, R. J., M. F. Hipkins, W. McDonald and T. G. Truscott (1981) Biochim. Biophys. Acta 634, 191202

Cogdell, R. J., J, G. Lindsay, J. Valentine and I. Durant (1982) FEBS Lett. 150, 151-154.

Cogdell, R. J., I. Durant, J. Valentine, J. G. Lindsay and K. Schmidt (1983) Biochim. Biophys. Acta 722, 427435.

Cohen-Bazire, G., S. Beguin, S. Rimon, A. N. Glazer and D. M. Brown (1977) Arch. Microbiol. 111, 225-238.

Cuendet, P. A., H. Zürrer, M. Snozzi and H. Zuber (1978) FEBS Lett. 88, 309-312.

Davidson, E. and R. J. Cogdell (1981) Biochim. Bio phys. Acta 635, 295-303.

Davidson, E., and R. J. Cogdell (1981) FEBS Lett. 132, $81-84$

Deisenhofer, J., O. Epp, K. Miki, R. Huber and M Michel (1984) J. Mol. Biol. 180, 385-398.

Erokhin, Yu. E. and A. A. Moskalenko (1973) Dokl. Acad. Nauk SSSR 212, 495-497.

Feick, R. and G. Drews (1978) Biochim. Biophys. Acta 501, 499-513.

Feick, R. and G. Drews (1979) Z. Naturforsch. 34c, 196-199.

Fenna R. E., L. F. Ten Eyck and B. W. Matthews (1977) Biochim. Biophys. Res. Comm. 75, 751-756.

Glazer, A. N. (1983) Ann. Rev. Biochemistry 52, 125157.

Gogel, G. E., P. S. Parkes, P. A. Loach, R. A. Brunisholz and H. Zuber (1983) Biochim. Biophys. Acta 746, $32-39$.

Gottstein, J. and H. Scheer (1983) Proc. Natl. Acad. Sci. USA 80, 2231-2234.

Hayashi, H. and S. Morita (1980) J. Biochem. 88, 1251-1258.

Hayashi, H., T. Nozawa and M. Hatano (1981) J Biochem. 89, 1853-1861.

Hayashi, H., M. Miyao and S. Morita (1982) J. Biochem. 91, 1017-1027.

Hayashi, H., T. Nozawa, M. Hatano and S. Morita (1982) J. Biochem. 91, 1029-1038.

Jap, B. K., M. F. Maestre, S. B. Hayward and R. M. Glaeser (1983) Biophys. J. 43, 81-89.

Jay, F., W. Stark, M. Lambillotte, F. Wyss and K. Mühlethaler (1984) Experientia 40,627.
Jennings, R. C., F. M. Garlaschi, G. Forti and P. D Gerola (1979) Biochim. Biophys. Acta 581, 87-95.

Kramer, H. J. M., R. V. Grondelle, C. N. Hunter, W. H. J Westerhuis and J. Amesz (1984) Biochim. Biophys. Acta 765, 156-165.

Miller, K. R. (1982) Nature 300, 53-55.

Miyazaki, T., S. Morita, M. Hatano and T. Nozawa (1979) J. Biochem. 86, 1411-1417.

Miyazaki, T. and S. Morita (1981) Photosynthetica 15. 238-243.

Morita, S., M. Edwards and J. Gibson (1968) Biochim. Biophys. Acta 189, 45-58.

Moskalenko, A. A. and Y. E. Erokhin (1978) FEBS Lett. 87, 254-256.

Niederman, R. A. (1983) Workshop on Molecular Structure and Function of Light-Harvesting PigmentProtein Complexes and Photosynthetic Reaction Centers, Abstr. II-3, ETH Zürich.

Olson, J. M. (1978) In The Photosynthetic Bacteria (Edited by R. Clayton and W. R. Sistrom), Chapter 8 , Plenum Press, New York

Peters, J. and G. Drews (1983a) FEMS Microbiol. Lett. 17, 235-237.

Peters, J. and G. Drews (1983b) FEBS Lett. 162, 57-60.

Pfennig, N. (1969) J. Bacteriol. 99, 597-602.

Philipson, K. D. and K. Sauer (1973) Biochemistry 12, 535-539.

Picorel, R., G. Belanger and G. Gingras (1983) Biochemistry 22, 2491-2497.

Picorel, R., S. Levebvre and G. Gingras (1984) Eur. J. Biochem. 142, 305-311.

Provencher, S. W. and J. Glöckner (1981) Biochemistry 20, 33-37

Sauer, K. (1975) In Bioenergetics of Photosynthesis, (Edited by Govindjee) Academic Press, New York.

Sauer, K. and L. A. Austin (1978) Biochemistry 17, 2011-2019.

Saxena, V. P. and D. B. Wetlaufer (1971) Proc. Nat Acad. Sci. USA 68, 969-972.

Scherz, A. and W. W. Parson (1984a) Biochim. Biophys. Acta 766, 653-665.

Scherz A. and W. W. Parson (1984b) Biochim. Biophys. Acta 766, 666-678.

Schmidt, K., N. Pfennig and S. Liaaen-Jenssen (1965) Arch. Mikrobiol. 52, 132-146.

Shiozawa, J. A., W. Welte, N, Hodapp and G. Drews (1982) Arch. Biochem. 213, 473-485.

Steiner, R. and H. Scheer (1985) Biochim. Biophys. Acta 807, 278-284.

Suzuki, Y., S. Morita and A. Takamiya (1969) Biochim. Biophys. Acta, 180, 114-122.

Tadros, M. H., F. Suter, G. Drews and H. Zuber (1983) Eur. J. Biochem. 129, 533-536.

Tadros, M. H., F. Suter, H. H. Seydewitz, I. Witt, H. Zuber and G. Drews (1984) Eur. J. Biochem. 138, 209-212.

Takemoto, J. Y., J. Peters and G. Drews (1982) FEBS Lett. 142, 227-230.

Theiler, R., F. Suter, H. Zuber and R. J. Cogdell (1984) FEBS Lett. 175, 231-237.

Thornber, J. P. (1970) Biochemistry 9, 2688-2698.

Thornber, J. P., R. J. Cogdell, R. E. B. Seftor, B. K Pierson and E. M. Tobin (1984) In Advances in Photosynthesis, (Edited by L. Sybesma) Vol. II, pp. 25-32. Nijhoff/de Junk, Dordrecht.

Tonn, S. J., G. E. Gogel and P. A. Loach (1977) Biochemistry 16, 877-885.

Vadeboncoer, N., H. Noel, Y. Cloutier and G. Gingras (1979) Biochemistry 18, 4301-4308.

van Grondelle, R., C. N. Hunter, J. G. C. Bakker and H. J. M. Kramer (1983) Biochim. Biophys. Acta 723, 3036.

Wiemken, V. and R. Bachofen (1982) Biochim. Biophys. Acta. 681, 72-76. 